\title{
A SUBJETIVAÇÃO DE MULHERES COM DEFICIÊNCIA MOTORA CONGÊNITA: O PAPEL DO OUTRO E DOS PROCESSOS FORMATIVOS
}

THE SUBJECTIVATION OF WOMEN WITH CONGENITAL MOTOR DEFICIENCY: THE ROLE OF OTHER AND FORMATIVE PROCESSES INFLUENCE

LA SUBJETIVACIÓN DE MUJERES CON DISCAPACIDAD MOTORA CONGÉNITA: EL PAPEL DEL OTRO Y DE LOS PROCESOS FORMATIVOS

\author{
Daniela de Lima Moura* \\ Silvia Rodrigues Cavalcanti Alves* \\ Sandra Patrícia Ataide Ferreira ${ }^{* * *}$
}

\begin{abstract}
RESUMO
Este estudo buscou compreender como se constitui o processo de subjetivação de adultos com deficiência motora congênita, participantes de uma ONG voltada a pessoas com deficiência. Participaram duas mulheres adultas, de 37 e 47 anos, com deficiência motora congênita, frequentadoras de um espaço educacional não formal, localizado na Zona Oeste do Recife-PE. Para a construção dos dados, utilizou-se o método narrativo de entrevista, fundamentando a análise na proposta dos núcleos de significação, de base sócio-histórica. Os resultados revelaram que a educação não formal e a educação informal estiveram mais presentes no processo de subjetivação dessas mulheres que a educação formal, e que os outros significativos não eram pertencentes à família e se configuraram como agentes essenciais na constituição dessa subjetivação. Ademais, verificou-se que essas mulheres têm diferentes trajetórias, gostos e interesses, constituindo-se como seres singulares, não sendo a deficiência o elemento definidor dessa subjetivação.
\end{abstract}

Palavras-chave: Deficiência motora. Núcleo de significação. Processos de subjetivação.

\footnotetext{
ABSTRACT

This study aimed at comprehending how establish the subjectivation process of adults with congenital motor deficiency that participated in a nongovernmental organization (NGO) which serves people with disabilities. Research with 37 and 47-year-old adult women with congenital motor

Texto recebido em 19 de novembro de 2013 e aprovado para publicação em 11 de abril de 2016.

Psicopedagoga; pedagoga; Faculdade Joaquim Nabuco. E-mail: danis2crw@hotmail.com.

* Mestra em Psicologia Cognitiva; Pedagoga; Universidade Federal de Pernambuco (UFPE). E-mail: silvinharca@hotmail.com.

*** Doutora em Psicologia Cognitiva; professora no Departamento de Psicologia e Orientação Educacionais, Centro de Educação, e no Programa de Pós-graduação em Psicologia Cognitiva da UFPE. E-mail: tandaa@terra.com.br.
} 
deficiency. They attend a non-formal educational space localized in the west of Recife-PE. For attainment of data, was used narrative interview method basing the analysis on the core of meaning proposal of socio-historical foundings. Results of the research revealed that non-formal education and informal education were more prominent in the subjectivation of these women than formal education. Moreover, it has been shown that their family were not a significant factor, despite the noteworthiness of others characterized as essential agents in their subjectivation construction. Furthermore, it was verified these women have different paths, different tastes and interests, which definite them as singular and their disability was not a fundamental element in their subjectivation constitution.

Keywords: Motor deficiency. Core meaning. Subjectivation processes.

\section{RESUMEN}

Este estudio ha buscado comprender como se constituye el proceso subjetivo de adultos con discapacidad motora congénita, participantes de una ONG centrada en atender a personas con discapacidad. Participaron dos mujeres adultas, de 37 y 47 años, con discapacidad motora congénita, que asisten a un espacio educacional no formal, localizado en la Zona Oeste de la ciudad de Recife-PE. Para construir los datos se ha utilizado el método narrativo de entrevista, basando el análisis en la propuesta de los núcleos de significado, de base socio-histórica. Los resultados han revelado que la educación no formal y la educación informal estuvieron más presentes en el proceso de subjetivación de esas mujeres que la educación formal y que los otros significativos no pertenecían a la familia y se configuran como agentes esenciales en la constitución de esa subjetivación. Además, se ha verificado que esas mujeres tienen trayectorias, gustos e intereses distintos que las constituyen como seres singulares no siendo la discapacidad el elemento que define esa subjetivación.

Palabras clave: Discapacidad motora. Núcleos de sentido. Procesos de subjetivación.

\section{INTRODUÇÃO}

$\mathrm{m}$ uma retrospectiva histórica, percebemos que o homem sempre apresentou dificuldades em lidar com questóes que fogem ao seu padrão de normalidade, excluindo do cenário social indivíduos tidos como "diferentes". Nesse grupo, além daqueles excluídos por sua etnia, religião, cultura, etc., encontramse também as pessoas com deficiência. Ao longo dos anos, pessoas com qualquer tipo de deficiência (física, intelectual ou sensorial) têm sido barradas do convívio social, sendo asiladas em instituições de cunho religioso e, ou, 
filantrópico. Desse modo, as pessoas com deficiência sempre tiveram sua imagem associada à incapacidade, à limitação e à doença, sendo o foco de atendimento a esses indivíduos as suas limitações e não as suas possibilidades.

No ano de 1981, porém, com a declaração do Ano Internacional das "Pessoas Deficientes", realizada pela Organização das Nações Unidas (ONU), e em 1994, com a Declaração de Salamanca Organização das Nações Unidas para a Educação, a Ciência e a Cultura (UNESCO), cresceram as discussões acerca da inclusão e do modelo social da deficiência, o qual, segundo Santos (2015), considera a questão da deficiência como um problema socialmente construído, relacionado aos obstáculos à integração plena dos indivíduos na sociedade.

Esse modelo ganhou bastante força, ressignificando sua concepção e mudando, em certa medida, o cenário no qual se apresentava tal temática. Assim, para incluir as pessoas com deficiência, foram criados vários aparatos de expedientes legais e humanitários, que visam a assegurar direitos civis a esses indivíduos historicamente excluídos.

Entretanto percebemos que essas representaçōes legais, muitas vezes, têm se transformado em medidas paliativas, que são disfarçadas por diferentes eufemismos, mascarando estratégias conservadoras de normatização. Ainda hoje, as pessoas com deficiência são tratadas como um grupo homogêneo, definido por estereótipos delimitadores, sendo assim violadas em sua identidade, pois, ainda que compartilhem uma mesma situação, não há homogeneidade entre essas pessoas. Desse modo, a pessoa com deficiência deve ser vista como um ser em relações sociais, que pode ressignificar sua identidade e concretizá-la de maneira positiva.

Do acima exposto derivam-se inquietações e o interesse por uma pesquisa voltada para o sujeito com deficiência, pois, em um levantamento na literatura da área, verificou-se uma escassez de estudos voltados a essa parcela da população, sendo estes, em grande parte, voltados a questôes como a dos direitos das pessoas com deficiência e, ou, da acessibilidade (Sassaki, 1999) e tendo como participantes pessoas que não têm deficiência (como especialistas, professores, pais, etc.) e não os mais interessados nessa questão, as próprias pessoas com deficiência. Tornam-se, assim, trabalhos sobre a deficiência sem envolver, no entanto, sujeitos com deficiência.

Assim, aborda-se o processo de subjetivação de adultos com deficiência motora congênita, participantes de uma organização não governamental (ONG) voltada à pessoa com deficiência, com a pretensão de se compreender para além da especificidade da deficiência, a singularidade que marca a história de vida de cada indivíduo. Entende-se que, ao negociar com os limites corporais que lhe são 
impostos, a pessoa encontra na deficiência um poderoso artifício de subjetivação, e os espaços que frequenta, como a ONG acima citada, constituem-se como importantes contribuintes para a construção dessa subjetivação, pois o homem constitui a sua subjetivação de acordo com a sua experiência e a sua interação com o mundo, sejam pessoas com deficiência ou não (Gomes \& Rey, 2008).

Portanto se procura responder, pela perspectiva das próprias pessoas com deficiência, as seguintes questôes: qual o papel dos processos formativos nesse processo de subjetivação? Quais os outros significativos envolvidos nesse processo? Tais questionamentos levaram a ter como objetivo principal: compreender as trajetórias de subjetivação de mulheres com deficiência motora congênita, participantes de uma ONG voltada à pessoa com deficiência. Para tanto, definiram-se os seguintes objetivos específicos: analisar o papel dos processos formativos formais e não formais na constituição dessa subjetivação e identificar quais são os outros significativos envolvidos nesse processo.

Acredita-se que este seja um importante passo para a geração de novos sentidos e configuraçóes sociais para as pessoas com ou sem deficiência, contribuindo para desmistificar a concepção de que as pessoas com deficiência são seres descaracterizados de sua condição social de sujeito e de cidadãos possuidores de gênero, idade, etnia e sexualidade.

\subsection{Subjetivação: constituição do ser na perspectiva sócio-histórica}

A subjetivação é a maneira particular e específica de compreensão do ser humano em sua totalidade, pois considera os aspectos culturais, sóciohistóricos, econômicos e individuais na produção de sentidos acerca daquilo que o homem tem de mais íntimo (Rey, 2003). A subjetivação, de acordo com a teoria vigotskiana, diz respeito à síntese singular e individual que cada pessoa vai constituindo, conforme se desenvolve e vivencia as experiências da vida social. Nesse sentido, de acordo com Bock, Furtado e Teixeira (1996), a maneira de sentir, pensar, sonhar, amar e fazer de cada pessoa é um importante elemento constitutivo do ser.

Ademais, a abordagem subjetiva do indivíduo possibilita a compreensão da esfera psicológica dentro de uma análise multidimensional, adotando uma simultaneidade do espaço social e do espaço individual, resgatando a processualidade necessária para a compreensão do desenvolvimento humano. Pensar em processos de subjetivação significa ampliar o olhar para a multiplicidade de elementos e dispositivos que perpassam o sujeito ao longo da vida (Bock, Furtado \& Teixeira, 1996). 
Esta visão da subjetivação implica não somente indivíduos, mas acontecimentos, situações, configurações sociais, produzidos por instâncias individuais, coletivas e institucionais. De tal modo que, conforme vamos experienciando o mundo social e cultural, construímos o nosso mundo interior, sendo diversos os fatores que se combinam e nos levam a uma vivência muito particular a partir da atribuição de sentido a essa experiência (Bock, Furtado \& Teixeira, 1996). De acordo ainda com esses autores, a subjetivação não é apenas moldada, mas também automoldável, pois o homem pode promover novas formas de subjetivação, recusando-se ao assujeitamento e à massificação que exclui e estigmatiza o diferente.

No que se referem aos estudos sobre a subjetivação de pessoas com deficiência, Gomes e Rey (2008) realizaram uma pesquisa que teve por meta explorar os sentidos subjetivos de um aluno com deficiência intelectual acerca do seu processo de inclusão, sendo esse sujeito um adolescente de 16 anos de idade, matriculado na $7^{\text {a }}$ série do ensino fundamental da rede regular de ensino. Puderam constatar, pela realização de sistemas conversacionais durante o período de sete meses, que uma das maiores dificuldades do aluno no processo de inclusão escolar estava na organização simbólica da própria instituição, que se estruturava muito mais como uma prática social e compensatória do que formadora ao aluno, ao aumentar sua diferenciação, não considerando adequadamente a sua singularidade.

Mello e Maluf (2009), numa abordagem antropológica, trataram dos processos de subjetivação em torno da experiência da deficiência, com o objetivo de abordar questóes relativas à constituição social nessa experiência, focando a construção da pessoa, do corpo, da subjetivação e da saúde mental, no sentido de compreender como essas questôes se articulam na manifestação da deficiência como identidade política. Os participantes da pesquisa foram três pessoas com deficiência (um homem com deficiência adquirida: amputação das duas pernas em tenra idade; e duas mulheres com deficiência congênita: baixa visão e cegueira total) e dois profissionais da Associação dos Deficientes Físicos de Florianópolis (AFLODEF), os quais foram entrevistados individualmente. Os resultados indicaram que "mais do que autoaceitação do sujeito, esse processo de subjetivação em torno da experiência da deficiência está intimamente relacionado com a capacidade do ser humano em superar-se, adaptar-se e construir atitudes positivas a partir das adversidades da vida" (Mello \& Maluf, 2009, p. 10).

Em outro estudo, Mendes (2007) se propôs a compreender os processos de subjetivação após a ocorrência de uma lesão medular, focalizando como o indivíduo se subjetiva depois de um acontecimento como esse. Por meio de entrevistas nos moldes de histórias de vida com duas pacientes do Centro de Reabilitação (uma com tetraplegia, 21 anos; e a outra com paraplegia, 32 anos), 
pôde concluir que ambas estavam processualmente reconstruindo suas vidas, fazendo suas escolhas, colocando-se novamente como "senhoras" de suas histórias e que os processos de transformação vivenciados pelas entrevistadas "marcaram, para além das mudanças do corpo físico, a importância dos atravessamentos do saber" (Mendes, 2007, p. 147).

Esses estudos demonstram que a compreensão da subjetivação de pessoas com deficiência vem a desafiar as investigações que têm como foco o processo de inclusão porque ressaltam as vivências particulares dessas pessoas, que, como se sabe, há muito, são reféns de atribuições e configurações sociais que as desconsideram como sujeitos ativos e construtores das próprias trajetórias de vida. Ressalta-se, assim, que não há necessariamente identidade de interesses entre pessoas com deficiência. Cada pessoa é única no seu modo de pensar, querer, sentir. Portanto não se devem igualar as pessoas por suas características, mas respeitar seu direito de ser diferente.

\subsection{Deficiência: a produção de sentidos sobre a pessoa com deficiência: do biológico ao social}

O olhar sobre a deficiência e o como lidar com ela vem passando por modificações ao longo dos anos. Há alguns anos, predominava na sociedade o modelo médico de interpretação da deficiência, que enxergava as pessoas com deficiência como doentes, focando apenas nos seus aspectos biológicos. Esse modelo designa o papel desamparado e passivo de pacientes, considerando-os como dependentes, incapazes, isentos dos deveres morais e detentores de vidas inúteis. Dessa forma, a deficiência é vista como um problema exclusivo de pessoas com deficiência, bastando prover-lhes algum tipo de serviço para solucioná-lo (Sassaki, 1999). Elenca-se também a influência do modelo caritativo da deficiência, o qual tratava a pessoa com deficiência como coitada, digna de pena e ajuda, por ser vítima da sua incapacidade, sendo, portanto, assim como no modelo médico, necessários serviços e espaços institucionais especiais para dar apoio aos "diferentes" (Lanna Júnior, 2010).

Entretanto, a partir do final da década de 1960, iniciou-se um movimento com vistas à inserção de pessoas com deficiência nos sistemas sociais gerais, como a educação, o trabalho, a família e o lazer, com o surgimento do modelo social da deficiência apontando criticamente para o modo como a sociedade desconsidera a diversidade e exclui as pessoas com deficiência dos meios sociais (Augustin, 2012).

No modelo social, os problemas advindos da deficiência não estão concentrados no indivíduo, mas sim na sociedade, que cria barreiras e causa desvantagens no desempenho dos papéis sociais de tais sujeitos, percebendo-se, desse modo, a evolução nas discussões sobre a deficiência (Sassaki, 1999). 
Contudo é importante entender que, até hoje, a exclusão e a segregação são praticadas em diferentes segmentos da sociedade, ainda que de maneira mais sutil e disfarçada. Por isso é bastante forte o movimento que visa a garantir mudanças na sociedade, no sentido de constituir esforços e adequaçóes às necessidades e habilidades de todas as pessoas, para que estas sejam aceitas e respeitadas com todas as diferenças que fazem delas seres humanos únicos.

De acordo com a Convenção sobre os Direitos das Pessoas com Deficiência (como citado em Carneiro, 2012), a deficiência resulta da interação dessas pessoas com as barreiras arquitetônicas e atitudinais que impedem a plena e efetiva participação na sociedade. Quanto à deficiência motora, tipo de deficiência dos sujeitos-foco desta investigação, esta é caracterizada como uma disfunção física que afeta o indivíduo, no que diz respeito à mobilidade, podendo ter origem em alterações dos grupos musculares, da estrutura óssea, da estrutura ósseo-articular ou em anomalias do sistema nervoso central. Considera-se uma pessoa com deficiência motora aquela que tenha essa deficiência no nível dos membros superiores ou inferiores, podendo apresentar-se em vários tipos, como a amputação, que é a falta de algum membro do corpo; a monoplegia, que diz respeito à paralisia em um membro do corpo; a hemiplegia, que paralisa metade do corpo; a paraplegia, que afeta da cintura para baixo; e a tetraplegia que paralisa o indivíduo do pescoço para baixo (Silva, 2009).

Em sua abordagem histórico-cultural, que revolucionou a concepção de deficiência da época, Vigotski (2004) defendeu o desenvolvimento das potencialidades no processo de aprendizagem individual, afirmando que a deficiência estimula os processos compensatórios, mediante um ambiente propício e acolhedor. $\mathrm{O}$ autor afirma que, pela compensação social, o indivíduo com deficiência pode superar a sua limitação, encontrando novos caminhos para o seu desenvolvimento. Assim, toda deficiência, seja ela mental ou física, origina estímulos para a formação da compensação. Nesse sentido, o "déficit" acaba saindo de foco, enaltecendo-se a capacidade do indivíduo com deficiência.

\section{PROCEDIMENTOS METODOLÓGICOS}

Participaram duas mulheres adultas com deficiência motora congênita, com 37 e 47 anos, sendo ambas negras e de origem humilde, frequentadoras de um espaço educacional não formal, voltado a pessoas com deficiência, localizado na Zona Oeste do Recife. A instituição, que existe há cerca de 30 anos, está fundamentada nos princípios da religião evangélica e comporta uma casa que serve de moradia para alguns de seus participantes, como é (foi) o caso das duas participantes desta pesquisa.

Para a construção de dados, utilizou-se o método narrativo, de caráter qualitativo, com o objetivo, como nos aponta Carneiro (2007), de acessar a 
história de vida dos participantes e valorizar as suas experiências subjetivas, a partir de pontos de vistas singulares acerca da subjetivação, emoção, cotidiano. Com esse tipo de método, segundo a autora, "a relação entrevistador-narrador rompe com a tradicional relação entrevistador-entrevistado. Tira o sujeito que narra do papel de mero informante e confere-lhe um lugar de produtor de sua história" (Carneiro, 2007, p. 51).

Para propiciar o início da produção da narrativa pelas participantes desta pesquisa, foi proposta a seguinte questão: “Como é a tua história de vida?”. Com base na resposta a essa pergunta inicial, foram-se explorando e aprofundando os aspectos apontados por elas, por meio de novas questôes. Cada participante foi ouvida individualmente por uma pesquisadora e em local previamente selecionado pelas entrevistadas, de modo que se sentissem à vontade para expor sua história de vida.

Para a análise dos dados, sustentou-se na proposta dos núcleos de significação, sistematizada por Aguiar e Ozella (2006), a qual tem como fundamento a abordagem sócio-histórica de Vigotski. De acordo com essa proposta, a análise não se fundamenta na apreensão de uma única resposta, coerente, absolutamente definida, completa, mas em expressōes do sujeito, muitas vezes contraditórias, parciais, que nos apresentam indicadores das formas de ser do sujeito, de processos vividos por ele. Então, para a análise dos núcleos de significação, deve-se partir das palavras inseridas no contexto que atribui significado aos sujeitos, sendo esse contexto a narrativa do sujeito e suas condiçôes histórico-sociais.

Os procedimentos para a análise dos núcleos de significação envolvem três etapas: identificar os pré-indicadores, que são palavras significativas, repetidas ou reiteradas, enfatizadas na fala do informante pela sua carga emocional; definir os indicadores (conteúdos temáticos), processo de aglutinação dos pré-indicadores pela similaridade, pela complementaridade ou pela contraposição; e, por fim, o processo de articulação, que resultará na organização dos núcleos de significação, por meio de sua nomeação.

\section{RESULTADOS E DISCUSSÃO}

A produção de sentidos do sujeito com deficiência motora congênita foi explorada tendo em vista os objetivos pretendidos bem como o contexto social em que as participantes estão inseridas. Buscou-se, assim, identificar os elementos comuns e diferentes registrados na trajetória de vida dessas pessoas com deficiência, a fim de que esses pudessem representar um sentido a mais na compreensão da constituição da subjetivação dessas mulheres. Para tal, os 
dados foram organizados por participante, apresentadas com nomes fictícios, destacando-se, inicialmente, uma breve história de vida e, em seguida, a análise da entrevista, como apresentado a seguir.

\subsection{Primeira participante}

\subsubsection{Uma breve história de Cláudia}

Cláudia é natural do Paraguai, tem 37 anos, provém de uma família humilde, tem oito irmãos e é paraplégica. Aos 21 anos, ela veio para o Brasil (realizar uma cirurgia) e, desde então, mora no bairro da Estância, Zona Oeste do Recife. Mãe de dois filhos, é divorciada e, no turno da manhã, trabalha na biblioteca da instituição da qual faz parte.

\subsubsection{Núcleo de significação}

Objetivando a produção de sentidos e significados com base na história de vida narrada por Cláudia, definiram-se alguns pré-indicadores do seu discurso para iniciar o processo de análise: exploração da sua deficiência; vergonha de pedir esmola; revolta e mágoa da mãe; oportunidade de estudar e trabalhar; o evangelismo em sua vida; viagem para a Argentina e possibilidade de se operar; a vinda para o Brasil e a vontade de permanecer; o casamento, o divórcio e os seus filhos; a conquista de sua casa e o fato de ter seu próprio dinheiro. Pelo processo de aglutinação desses pré-indicadores, baseados nos critérios de semelhança, complementaridade e contradição, chegaram-se aos seguintes indicadores do discurso: a humilhação pela qual passou; a vinda para o Brasil; as condições de viver uma vida digna. Logo, com base nos procedimentos adotados, chegou-se a três núcleos de significação do discurso da participante: "Era muito humilhante o que minha mãe fez, muito chocante mesmo [...]"; a relação com a professora e com a Igreja evangelista; a vida no Brasil: casamento e filhos.

a) "Era muito humilhante o que minha mãe fez, muito chocante mesmo..."

Com a identificação desse núcleo de significação, foi possível identificar a mágoa que Cláudia tem devido à exploração que sofreu por parte de sua mãe, que a mandava às ruas do Paraguai, para pedir esmolas. Cláudia sente muita vergonha dessa etapa de sua vida, não tendo boas lembranças das experiências vivenciadas nessa época, ressaltando o quanto ela sentia-se ferida ao ouvir os comentários alheios, como podemos ver no trecho abaixo: 
É meio vergonhoso... porque foi muito chocante... eu venho de uma família muito simples, muito humilde. Aí, bom, a partir dos cinco anos, minha mãe começou se aproveitando... é muito forte, pra mim sempre foi... $E$, aproveitou da minha deficiência e me mandou no centro da cidade, lá no Paraguai, pra começar a pedir esmola desde pequenininha... E isso eu fui fazendo, a única coisa que eu aprendi da minha mãe como pedir. Aí, quando eu comecei a ficar adolescente, eu creio que com doze, doze anos, a vergonha, eu comecei a sentir a vergonha na pele, porque a maioria dizia assim: "Minha filha, porque tu não estuda, em vez de tá pedindo?, faça alguma coisa pra tá vendendo". Aí isso... Eu chegava em casa revoltada, chegava angustiada.

A mãe de Cláudia, por acreditar que ela era digna de pena, aproveitava-se da situação para conseguir um benefício, demonstrando, assim, a concepção caritativa, definida por Lanna Júnior (2010), a qual enxerga o sujeito com deficiência como coitado, que vive numa situação trágica, sendo destinado a viver da caridade alheia.

Entretanto a participante nos revela que foi nesse momento, nas ruas, que ela conheceu uma professora que a ajudou a sair daquela situação, disponibilizandose a ensiná-la e oferecendo-lhe um emprego na loja da qual era dona. Tal acontecimento foi um dos primeiros passos na mudança que ocorreu na história de Cláudia, pois a tornou mais independente e a fez sentir-se ativa, útil e capaz de guiar sua vida, sem necessitar da caridade de outros.

b) A relação com a professora e com a Igreja evangelista

A professora configurou-se como um importante outro significativo na vida de Cláudia, pois, além de proporcionar-lhe certa autonomia (dignas condições de sustento), ofereceu-lhe um conjunto de elementos constitutivos de sua subjetivação, pois, como sabemos, esta é construída internamente pelo indivíduo, por sua constituição biológica, suas relações sociais e suas vivências (Bock, Furtado \& Teixeira, 1996).

A partir do momento que se sentiu ativa na sociedade, Cláudia passou a frequentar uma igreja evangélica, ambiente informal que contribuiu para o seu desenvolvimento pessoal, proporcionando-lhe novas maneiras de pensar e agir, como ela mesma ressalta: "A partir do momento que comecei a frequentar a Igreja, a orar mais, aquele ódio que eu sentia, Deus tirou tudinho de mim. Tirou tudo. Só que aí ninguém esquece, mas a mágoa, graças a Deus, não fica, não guardo não". 
Entretanto, durante a narração da participante, fica clara também a existência de uma relação contraditória entre seus sentimentos e sua religião. Apesar de enfatizar que o evangelismo a tornou uma pessoa melhor, retirando-lhe a mágoa e concedendo-lhe a capacidade de perdão, Cláudia se mostra extremamente magoada com tudo que ela viveu, principalmente em relação à sua mãe, demonstrando orgulho de poder estar em uma situação melhor do que aquela que vivia junto a sua família e expressando o desejo de mostrar a superação em sua vida à sua mãe, como podemos observar no trecho a seguir:

Cláudia: Quando marcaram a data e tudo, eu toda animada, e olhe que eu não tinha nenhum documento, nada, sei lá, se não fosse esse pastor que me ajudasse, sei lá, eu não ia ser ninguém na vida, sem nada.

Entrevistadora: A partir deles, foi que tu tiraste os documentos?

Cláudia: Graças a eles, foram tudo eles. Pra você ver, minha mãe era tão irresponsável, é duro falar assim, mas eu falo, não é porque eu não gosto da minha mãe, ao contrário, eu já perdoei ela por tudo isso, mas coisas que marcam minha vida que eu não esqueço... Eu quero, ainda não tirei da cabeça de um dia ela vir aqui e eu mostrar a ela que aquela menina deficiente que era esmoleu, não tinha nada, não era ninguém... Mas tô assim, na minha casinha, tentando viver uma vida digna, não pedindo dinheiro, é isso que queria mostrar a ela.

Cláudia nos deixa claro o quanto se orgulha da sua superação e, ao longo de seu discurso, percebe-se a importância que os seus amigos (outros significativos) tiveram nesse processo, possibilitando-lhe, inclusive, a vinda para o Brasil e a estada na instituição em que vive. Tal instituição, ainda que não tenha funcionado para Cláudia como espaço educativo de sistemática aquisição de conhecimentos e capacidades, foi imprescindível em termos de proporcionar-lhe uma efetiva participação no convívio social, servindo-lhe de abrigo quando ela precisou e dando-lhe oportunidade, pelo emprego na biblioteca, de crescer economicamente e consolidar sua autonomia. Ademais, identifica-se também a Igreja como um ambiente fundamental no processo de subjetivação de Cláudia, pois o lugar se configurou como espaço educacional informal que, como nos afirma Gohn (2006), é propício para o desenvolvimento de hábitos, comportamentos, valores, crenças e linguagem.

Vale ressaltar também que foi na Igreja onde Cláudia conheceu o pastor Edmilson, brasileiro que pastoreava no Paraguai e que se interessou por sua história, e despertou-lhe o desejo de investigar sobre sua deficiência e realizar sua cirurgia. Edmilson foi quem idealizou a viagem para a operação de Cláudia na Argentina, a qual não pôde ocorrer, frustrando-a, e quem, por outro lado, 
possibilitou a vinda dela para o Brasil, arrumando-lhe abrigo e uma pessoa que lhe servisse de apoio (Íris). Dessa forma, Cláudia se afeiçoou a esse pastor, pois, além de ter sido ele o responsável por todos os trâmites legais que possibilitaram sua viagem e sua operação, ele se caracterizava como uma figura de afeto, que lhe oferecia cuidados e atenção, os quais ela não tinha experimentado até o momento:

Aí claro que me apeguei muito a esse pastor, porque coisa que eu não tinha na minha família era apoio; amor dos meus pais, eu nunca encontrei, o que não encontrei neles eu encontrei na família do pastor. Aí me apeguei muito a eles [...] e ele me falou de Íris. Que ele conheceu uma entidade para deficiente físico e iria perguntar a ela se tinha a possibilidade de ser interna..., de ir pra ser hospedada aqui, fazer meu tratamento. Aí, graças a Deus, o pastor falou pra Íris; me receberam com os braços abertos. Vim, fiz três cirurgias.

Dessa forma, percebe-se que a professora, o pastor e Íris foram extremamente importantes na vida de Cláudia, configurando-se como outros significativos que colaboraram para a construção do seu mundo interior, possibilitando-lhe novas experiências, novas relações sociais, que lhe ajudaram na sua constituição particular (Bock, Furtado \& Teixeira, 1996).

\section{c) A vida no Brasil: casamento e filhos}

Evidenciando ainda mais as contribuições de Íris para a sua vida, Cláudia afirma que decidiu ficar no Brasil porque aqui ela tinha o que nunca havia encontrado no Paraguai: uma família e perspectivas de melhora de vida. Assim, Cláudia morou por um tempo na instituição e, depois de se casar, contra a sua vontade, unicamente para poder viver no Brasil, ela passou a morar numa casa alugada com o seu então marido, com o qual não teve experiências positivas, ressaltando que a única coisa boa que ela guardou desse relacionamento foram seus filhos:

Com ele (ex-marido), não consegui nada. Nada! Que foi um engano mesmo, eu acho. Porque não era pra ser mesmo. A única coisa é meus dois filhinhos, que, graças a Deus, que é uma benção, mas ele [...]

Aí o que me ajuda é o dinheirinho extra que ganho na biblioteca. E consegui botar isso, troquei as portas e, quando meu ex-marido veio, ele olhou e disse assim: "Puxa, Cláudia, tô vendo que tu não precisa de homem". Aí eu disse: "Eu preciso de Deus, pra tu ver como Deus existe, porque, se fosse depender de você, eu não tinha nada". Eu tive que dizer, mas ele ficou calado, vai dizer o quê? É isso aí! 
Cláudia enfatiza o quanto as coisas começaram a melhorar na sua vida após o seu divórcio, como a conquista da sua casa própria e a possibilidade de organizála do seu jeito, com o dinheiro de seu trabalho. Desse modo, verificamos uma relação de complementaridade entre a vontade de Cláudia permanecer no Brasil, o casamento, os seus filhos e o divórcio, elementos os quais estiveram presentes na sua vida e marcaram (positivamente ou não) a sua trajetória.

De tal modo, fica evidente a mudança que ocorreu na vida dessa participante, que pôde ressignificar o conceito que tinha de si mesma. Antes considerada como incapaz e dependente, hoje Cláudia se vê ativa e competente, e se orgulha de conseguir superar as dificuldades que a vida lhe impóe.

\subsection{Segunda participante}

\subsubsection{Uma breve história de Eliza}

Eliza tem 47 anos e, há 12, participa da instituição voltada para pessoas com deficiência motora, situada no bairro da Estância, Zona Oeste do Recife, onde mora atualmente. Ela tem paraplegia, cursou até o $5^{\circ}$ ano do ensino fundamental e hoje é atleta do paraesporte.

Para iniciar o processo de análise, visando à produção de sentidos e significados dessa participante, foram definidos os seguintes pré-indicadores de seu discurso: dificuldades na infância; convivência com seus limites; preconceitos vivenciados; movimento de aceitação e autoaceitação; o paraesporte; oportunidade de aproveitar a vida e de conhecer o mundo; sentimento de liberdade; a religião; o desejo de se casar. Da aglutinação desses pré-indicadores, de acordo com os critérios de semelhança, complementaridade e, ou, contraposição, chegaram-se aos seguintes indicadores do discurso: dificuldades e preconceitos enfrentados; aceitação da deficiência; o paraesporte como possibilidade de conhecer o mundo. Foram, então, definidos três núcleos de significação produzidos por Eliza: o preconceito vivido na infância; as experiências na adolescência; as relações afetivas e a participação na Igreja e na instituição não formal.

\section{a) O preconceito vivido na infância}

Pelo discurso de Eliza, pode-se perceber o quanto a deficiência marcou a sua história, caracterizando-se como forte elemento constitutivo de sua subjetivação, de maneira específica, em cada etapa da sua vida. Verificou-se que, na infância, Eliza manteve uma relação conflituosa consigo mesma, devido às dificuldades que a deficiência lhe acarretava, como a difícil locomoção, as cirurgias e o preconceito que vivenciava: 
Eliza: A minha infância foi difícil. A gente sempre marcava cirurgia e não dava certo. Achavam que eu não ia sobreviver, mas fiquei boa... Antes, eu não vou mentir pra você, eu era preconceituosa comigo mesma, eu vim conseguir minha primeira cadeira de rodas aqui na instituição.

Entrevistadora: Como assim, você não tinha antes?

Eliza: É por que eu não gostava, entendeu? Eu achava que as pessoas iam olhar pra mim diferente e meu pai também não queria.

Eliza não conseguia lidar bem com a sua deficiência, devido ao medo e à insegurança que sentia em relação à sua saúde. Essa situação revela a predominância do modelo médico, citado por Sassaki (1999), em que a imagem da pessoa com deficiência está relacionada à incapacidade, à doença e requer que o sujeito esteja sempre em tratamento e reabilitação médica, no intuito de "normalizá-lo", pois nessa concepção o foco está no déficit, sendo o indivíduo com deficiência quem deve ser mudado e não o ambiente ao seu redor, com a possibilidade de garantia de compensação social à deficiência biológica (Vigotski, 2004).

b) As experiências na adolescência

Eliza nutria um receio, alimentado pelo pai, da forma como as pessoas reagiriam e iriam se relacionar com ela ao vê-la em uma cadeira de rodas. Entretanto, percebe-se que sua fase da adolescência foi rica em experiências sociais e que Eliza passou a ter uma relação mais saudável consigo mesma e com os outros que a rodeavam:

Sempre tive liberdade pra sair, passeei muito. [...] Ah... eu ia pra feirinha, praia, discoteca, tomava uma cervejinha, namorei muito, aproveitei o tanto que deu, pegamos experiência, eu era tão virada que, com 12 anos, arrumei meu primeiro namorado, com 23.

Desse modo, Eliza foi produzindo os seus sentidos, aquilo que é singular ao indivíduo, a partir da apropriação dos significados, ou seja, dos elementos compartilhados, presentes no mundo cultural e social, ao mesmo tempo em que atuava sobre esse mundo, constituindo a sua subjetivação, pois, criando e transformando a realidade externa, o indivíduo vai transformando-se também, internamente (Bock, Furtado \& Teixeira, 1996). 
Nesse sentido, o primeiro namorado de Eliza aparece como o outro significativo que a ajudou no processo de autoaceitação, pois ele, demonstrando amá-la, conseguiu quebrar as barreiras e os estigmas que ela tinha acerca de sua deficiência. Ele exerceu uma influência bastante positiva no curso da história dessa participante, aparecendo como efetivo elemento constitutivo de sua subjetivação (Rey, 2004), como se pode verificar em seu discurso: "O primeiro (namorado), sim, me ensinou a aproveitar a vida. Ele me ajudou a me aceitar, a deixar as pessoas se aproximarem de mim, fazer amizades para sempre. Essa foi a melhor marca que ele me deixou".

Por outro lado, identificou-se uma relação de contradição no discurso de Eliza, referente a essa etapa de sua vida, pois, ainda que ela afirme que tenha tido liberdade para sair e realizar vivências sociais, percebe-se que o seu pai aparece constantemente como impedimento para a concretização de suas vontades, como explicitam os trechos abaixo:

Nunca gostei de me sentir presa, fugia de casa, pulava o muro, saía com os coleguinhas, voltava antes do meu pai. Eu sabia a hora que ele voltava do trabalho, aí eu voltava antes [...], mas meu pai achava que eu, nessas condições, não podia (namorar). [...] Aí foi até uma vez que um amigo do meu pai [...] comentou: "Sua filha tão bonita, não casou ainda?!". Aí ele disse: "Não, mas ela não quer casar não, ela quer ficar pra sempre com a gente". Aí eu revidei, eu disse: "Quem disse? Eu quero me casar, sim, só não casei ainda porque ainda não apareceu”.

Como vimos, as crenças e atitudes do pai de Eliza estavam muito relacionadas com a ideia de que a deficiência descaracteriza o indivíduo como sujeito possuidor de desejos, vontades e direitos, inclusive de apaixonar-se. Isso remete também à concepção caritativa da deficiência, abordada por Lanna Júnior (2010), em que a pessoa com deficiência é considerada vítima da sua incapacidade, impossibilitada de se ajudar e levar uma vida autônoma, que precisa de auxílio e de alguém sempre por perto, para tomar conta dela.

c) As relações afetivas e a participação na Igreja e na instituição não formal

Outro fator importante na vida de Eliza também foi a religião, que a fez mudar de atitudes e deu-lhe mais vontade de viver, como ela enfatiza:

Entrevistadora: E por que tu decidiste virar evangélica? O que mudou?

Eliza: Ah, mudou muita coisa! As amizades. Eu era briguenta, não desejava mal ao próximo, mas era rancorosa. Hoje em dia, eu não sou mais, eu era ignorante, hoje as pessoas me machucam, mas eu só choro e entrego a Deus, e hoje é mais alegria, mais ânimo de viver. 
Percebe-se, então, que a religião foi fundamental para a constituição subjetiva de Eliza, caracterizando-se como uma educação informal que a proporciona, por meio de valores e crenças, novas formas de pensar e agir, ajudando-lhe no desenvolvimento de novas condutas. Além disso, a partir do momento em que Eliza passou a frequentar a instituição e ganhou a sua cadeira de rodas, ela começou a sentir-se mais independente e passou a ter uma maior autonomia, tendo, inclusive, saído da casa dos pais para viver na instituição. Essa instituição, como um espaço educativo não formal, funciona para Eliza como um ambiente no qual ela sente-se verdadeiramente livre, onde constrói laços de pertencimento e que contribui para o desenvolvimento de sua identidade (Gohn, 2006).

Assim, identifica-se uma complementaridade entre o movimento de autoaceitação de Eliza, a aquisição de sua autonomia e de seu sentimento de liberdade, pois, hoje, por meio da instituição, ela vivencia diversas experiências e mostra-se realizada com as mudanças que essas experiências provocam em sua vida: "Porque aqui eu participo do paraesporte né? Viajo, viajei para Salvador, foi a melhor parte da minha vida. Consegui minhas medalhas e tô seguindo. Não tenho mais preconceito comigo".

Desse modo, ficou evidente o processo de mudança ocorrido na vida de Eliza, uma pessoa que, antes, não se aceitava, que enfrentou diversos obstáculos, entre eles o preconceito dela consigo mesma, inclusive do próprio pai, mas que hoje superou as suas dificuldades, graças a diversos fatores como: o primeiro namorado, a religião, a instituição e, consequentemente, o paraesporte. Acreditase que a instituição não governamental funcionou como um divisor de águas na vida de Eliza, garantindo-lhe maior independência e reconhecimento por meio das medalhas conquistadas, colaborando na ressignificação da sua história.

\section{CONSIDERAÇÕES FINAIS}

Tendo em vista o objetivo geral desta pesquisa, compreender como se constitui o processo de subjetivação de adultos com deficiência motora congênita, participantes de uma ONG voltada à pessoa com deficiência, foi possível constatar que a constituição dos processos de subjetivação por parte das mulheres com paraplegia, participantes desta pesquisa, ocorreu por meio de diversas vivências e experiências e no convívio com o meio social. Porém os caminhos percorridos variam de uma para outra, de acordo com suas escolhas, vivências e singularidades.

Verificamos que existem elementos na história de nossas participantes que as aproximam, como o tipo de deficiência, a paraplegia; a conquista da cadeira de rodas que, por proporcionar-lhes melhores condições de locomoção, 
caracterizou-se como um elemento significativo na vida das duas; a religião; a instituição não governamental da qual participam, etc. No entanto vale ressaltar que, ainda que a referida instituição tenha aparecido como importante elemento no discurso de todas as participantes, funcionando, segundo Vigotski (2004), como um elemento de compensação, ela teve efeitos distintos para cada uma delas, concretizando sua colaboração de diversas maneiras.

Identificaram-se peculiaridades no processo de subjetivação de cada uma de nossas participantes, uma vez que destacaram pontos bem diferentes ao se referirem à mesma instituição. Para Cláudia, fica evidente a importância do local para o desenvolvimento da sua autonomia, principalmente financeira. Para Eliza, a instituição proporcionou o reconhecimento de suas habilidades, por meio das medalhas e troféus ganhos no paraesporte. Tais dados mostram o quanto os significados compartilhados são reelaborados, dando lugar a novos sentidos, ou seja, a individualidade em meio à semelhança.

Ademais, percebeu-se que a educação não formal (ONG) e a educação informal (rua, Igreja, amigos, família, etc.) estiveram mais presentes e se apresentaram de forma mais efetiva na constituição da subjetivação das participantes, proporcionando-lhes experiências que marcaram suas vidas, do que a educação formal (escola). A escola como espaço de sistemática aquisição de conhecimentos esteve pouco presente na história das duas participantes e, mesmo quando aparece, é pela dificuldade que representava.

Quanto aos outros significativos presentes na vida das participantes desta pesquisa, esses tiveram fundamental importância nos progressos e mudanças vivenciados por elas. Para a participante Cláudia, foram a professora, o pastor e Íris (responsável pela instituição); já para Eliza, o namorado. Tais pessoas não faziam parte da família dessas mulheres, mas se configuraram como agentes essenciais na constituição da subjetivação de cada uma das participantes.

Com base nos dados analisados, pode-se perceber que a instituição não governamental aparece como um espaço importante no processo dessa constituição, bem como a religião, atuando de maneira distinta e específica para cada uma delas. A ONG lhes proporcionou, inclusive, uma efetiva participação no convívio social, dando-lhes oportunidade de potencializar suas capacidades e consolidar sua autonomia. O que está em convergência com o estudo de Mendes (2007) que, ao pesquisar sujeitos com deficiência motora adquirida, constatou subjetividades marcadas pela autonomia e por histórias de vida singulares.

Um aspecto da subjetivação das participantes que não apareceu explicitamente nos dados obtidos nesta pesquisa diz respeito à expressão da sexualidade, que não se mostrou significada por elas, ao falar da própria história de vida, com 
base no método narrativo de entrevista. O que aponta para sentidos não ditos, mas que não foram possíveis de se identificar com base no design metodológico assumido nesta pesquisa. Neste caso, sugere-se que estudos futuros possam explorar a temática da sexualidade com pessoas com deficiência motora ou outras deficiências, com base em um método de pesquisa mais diretivo. 


\section{REFERÊNCIAS}

Aguiar, W. M. J. \& Ozella, S. (2006). Núcleos de significação como instrumento para a apreensão da constituição dos sentidos. Psicologia, Ciência e Profissão, 26 (2), 222-245.

Augustin, I. (2012). Modelos de deficiência e suas implicações na educação inclusiva. Anais da 9 ANPED - SUL. UCS. Recuperado a partir de http:// www.ucs.br/etc/conferencias/index.php/anpedsul/9an pedsul/paper/ viewFile/1427/655.

Bock, A., Furtado, O. \& Teixeira, M. D. L. (1996). Psicologias: uma introdução ao estudo de Psicologia. São Paulo: Saraiva.

Carneiro, M. S. C. (2007). Deficiência mental como produção social: uma discussão a partir de histórias de vida de adultos com sindrome de Down. (Tese de Doutorado). Universidade Federal de Santa Catarina, Programa de PósGraduação em Educação, Florianópolis.

Carneiro, M. S. C. (2012). A Convenção sobre os Direitos das Pessoas com Deficiência e seus reflexos na ordem jurídica interna do Brasil. In C. V. Ferraz (Coord.). Manual dos direitos da pessoa com deficiência. São Paulo: Saraiva. (E-book).

Gohn, M. D. G. (2006). Educação não-formal, participação da sociedade civil e estruturas colegiadas nas escolas. Ensaio: avaliação e políticas públicas em educação, 14(50), 27-38. Recuperado a partir de http://www.scielo.br/pdf/ ensaio/v14n50/30405.pdf.

Gomes, C. \& Rey, F. L. G. (2008). Psicologia e inclusão: aspectos subjetivos de um aluno portador de deficiência mental. Revista Brasileira de Educação Especial, 14(1), 53-62.

Lanna Júnior, M. C. M. (Comp.). (2010). História do movimento político das pessoas com deficiência no Brasil. Brasília: Secretaria de Direitos Humanos, Secretaria Nacional de Promoção dos Direitos da Pessoa com Deficiência.

Mello, A. G. \& Maluf, S. W. (2009). Por uma abordagem antropológica da deficiência: pessoa, corpo e subjetividade. (Trabalho de Conclusão de Curso). Universidade Federal de Santa Catarina, Florianópolis.

Mendes, L. G. G. (2007). Subjetividade e lesão medular: vida que escapa à paralisia. (Dissertação de Mestrado). Pontifícia Universidade Católica de Minas Gerais, Programa de Pós-Graduação em Psicologia, Belo Horizonte. 
Rey, F. L. G.(2003). Sujeito e subjetividade: uma aproximação histórico-cultural. São Paulo: Thomson.

Rey, F. L. G. (2004). O social na Psicologia e a Psicologia social: a emergência do sujeito. Petrópolis: Vozes.

Santos, W. (2015). Modelo social, interdisciplinaridade e intersetorialidade: desafios às políticas sociais para a deficiência no Brasil. Brasília: Observatório Internacional de Capacidades Humanas, Desenvolvimento e Políticas Públicas. Recuperado a partir de http://capacidadeshumanas.org/oichsite/wp-content/ uploads/2015/06/11_defici--ncia-final.pdf.

Sassaki, R. K. (1999). Inclusão: construindo uma sociedade para todos. Rio de Janeiro: WVA.

Silva, L. C. (2009). Deficiências motoras. [S.1.]: Artigonal. Recuperado a partir de http://www.artigonal.com/medicina-artigos/deficiencias-motoras-tematcc-monografia-1275914.html.

Vigotski, L. S. (2004). Psicologia pedagógica. (2a ed.). (P. Bezerra, Trad.). (pp. 379-395). São Paulo: Martins Fontes. (Texto original publicado em 1926). 